\title{
XÂY DỰNG KICH BẢN BIẾN ĐỔI NHIỆT ĐỘ TRONG BỐI CẢNH BIẾN ĐỔI KHÍ HậU CHO KHU VỤ̉C TỈNH TÂY NINH
}

\author{
Lê Ngọc Tuấn ${ }^{1 *}$, Nguyễn Văn Tín², \\ Trần Tuấn Hoàng ${ }^{2}$, Phạm Thanh Long ${ }^{2}$, Nguyễn Kỳ Phùng ${ }^{3}$
}

Tóm tắt: Bằng phưong pháp thu thập, xử lý số liệu và phần mềm SimCLIM, các kịch bản biến đổi nhiệt độ trong bối cảnh biến đổi khi hậu (BĐKH) khu vực tỉnh Tây Ninh được xây dựng turong úng với các kịch bản RCP2.6 - RCP8.5. Kết quả cho thấy nhiệt độ trung bình (Ttb) gia tăng theo thòi gian và các kịch bản RCPs: khoảng 1,1-3,60 C vào năm 2100 so với giai đoạn 1986 - 2005. Trong đó, Ttb cao nhất phân bố chủ yếu ở khu vực phía tây của tỉnh (nhu huyện Tân Biên, Châu Thành). Bên cạnh đó, xu thế gia tăng nhiệt độ các tháng trong năm (đặc biệt là mùa khô) và nhiệt độ cực trị cũng được ghi nhận với mức tăng Tx nhanh hơn so với T.tb và T.m. Kết quả nghiên cưu là cơ sở quan trọng phuc vu đánh giá tác động và tính dễ bị tổn thuoong (DBTT) do sụ gia tăng nhiệt độ tại tỉnh Tây Ninh, đóng góp tích cưc vào việc hoạch định và kiện toàn hệ thống các giải pháp úng phó $B Đ K H$.

Từ khóa: Biến đổi nhiệt độ, nhiệt độ trung bình, nhiệt độ cưc trị, kịch bản BĐKH, nóng lên toàn cầu.

Ban Biên tập nhận bài: 20/10/2019 Ngày phản biện xong: 28/11/2019 Ngày đăng bài: 25/02/2019

\section{1. Đặt vấn đề}

Biến đổi khí hậu (BĐKH) biểu hiện bởi sự nóng lên toàn cầu, mực nước biển dâng (NBD) và gia tăng các hiện tượng khí tượng thủy văn cực đoan [1], đã và đang tác động trực tiếp đến đời sống kinh tế - xã hội (KTXH) và môi trường toàn cầu, là mối lo ngại của các quốc gia trên thế giới, trong đó có Việt Nam. Theo đó, nhiều nỗ lực nghiên cứu về $\mathrm{BĐKH} \mathrm{được} \mathrm{thực} \mathrm{hiện} \mathrm{từ} \mathrm{quy}$ mô địa phương, quốc gia, khu vực cũng như toàn cầu.

Việc nghiên cứu $\mathrm{BĐKH}$ có thể được chia thành ba nhóm lớn chính: (N1) Bản chất, nguyên nhân, cơ chế vật lý của sự BĐKH; (N2) Đánh giá tác động của BĐKH, tính DBTT do BĐKH và giải pháp thích ứng; (N3) Giải pháp, chiến lược và kế hoạch hành động nhằm giảm thiểu
$\mathrm{BĐKH} \mathrm{[2].} \mathrm{Về} \mathrm{logic,} \mathrm{nghiên} \mathrm{cứu} \mathrm{BĐKH}$ cần được thực hiện tuần tự, trong đó nhóm (N1) cần tiến hành đầu tiên với hai nhóm chính: (i) Xác định các bằng chứng, nguyên nhân gây $\mathrm{BĐKH}$ trong quá khứ và hiện tại; (ii) Đánh giá $\mathrm{BĐKH}$ trong tương lai bao gồm việc xây dựng các kịch bản BĐKH.

Kịch bản $\mathrm{BĐKH} \mathrm{là} \mathrm{giả} \mathrm{định} \mathrm{có} \mathrm{cơ} \mathrm{sở} \mathrm{khoa}$ học và tính tin cậy về sự tiến triển trong tương lai của các mối quan hệ giữa KTXH, GDP, phát thải $\mathrm{KNK}, \mathrm{BĐKH}$ và mực NBD [1]. Đến nay, Ủy ban Liên chính phủ về BĐKH (IPCC) đã thực hiện 5 lần xây dựng và cập nhật kịch bản $\mathrm{BĐKH}$ thông qua các lần báo cáo đánh giá $\mathrm{BĐKH.}$ Trong đó, sự thay đổi cơ bản của IPCC-AR5 liên quan đến các kịch bản phát thải KNK: RCPs (Representative Concentration Pathways) được

${ }^{1}$ Trưòng Đại học Khoa học Tự nhiên - Đại học Quốc gia Thành phố Hồ Chí Minh

${ }^{2}$ Phân viện Khoa hoc Khí tương Thủy văn và Biến đổi Khí hậu

${ }^{3}$ Sở Khoa hoc và Công nghệ thành phố Hồ Chí Minh

Email:lntuan@hcmus.edu.vn 
sử dụng để dự đoán khí hậu trái đất đến năm 2100, gồm RCP2.6, RCP4.5, RCP6.0 và RCP8.5 tương ứng với nồng độ KNK quy đổi thành khí $\mathrm{CO} 2$ là $490 \mathrm{ppm}, 650 \mathrm{ppm}, 850$ và 1370 ppm [1].

Các phương pháp áp dụng trong xây dựng kịch bản BĐKH bao gồm 2 phương pháp chính: (i) Phương pháp thống kê; (ii) Phương pháp mô hình động lực. Phương pháp thống kê đã phát triển tương đối sớm trong dự báo mùa. Cuối thế kỷ 19, mối quan hệ giữa hoạt động của mặt trời và thời tiết đã bắt đầu được quan tâm, đặc biệt là vấn đề dự báo mưa gió mùa (Monsoon rainfall), tiếp đó là vấn đề biến động của các hình thế khí áp trong vùng nhiệt đới $[3,4]$. Đến nay, các mô hình thực nghiệm dự báo mùa với nhiều phương pháp khác nhau đã được nhiều nhà khoa học nghiên cứu và phát triển [5-9]. Phương pháp thống kê là một công cụ ứng dụng khá phổ biến, có thể chia thành 3 nhóm [10]: Thống kê truyền thống; Hạ thấp quy mô thống kê (Chi tiết hóa thống kê) (Statistical Downscaling - SD); Thống kê trên sản phẩm mô hình (Model Output Statistics-MOS). Các mô hình khí hậu toàn cầu (GCM - Global Climate Model) và khu vực (RCM - Regional Climate Model) phát triển từ cuối những năm 1980. GCM là một mô hình toán học về tuần hoàn tổng quát của bầu khí quyển trái đất hoặc đại dương dựa trên các công thức toán mô tả các quá trình vật lý là cơ sở cho những chương trình máy tính phức tạp thường được sử dụng để mô phỏng bầu khí quyển và các đại dương trên trái đất [11-13]. Ứng dụng quan trọng nhất của các GCM nói chung là dự tính khí hậu tương lai (thế kỷ 2) dựa trên các kịch bản phát thải khí nhà kính - là cơ sở để xây dựng các kịch bản $\mathrm{BĐKH}$ [14].

Tỉnh Tây Ninh thuộc miền Đông Nam Bộ, nằm trong vùng kinh tế trọng điểm phía $\mathrm{Nam}$, là một trong những địa phương có tốc độ tăng trưởng kinh tế cao, phát triển công nghiệp năng động của cả nước. Kịch bản $\mathrm{BĐKH} \mathrm{tỉnh} \mathrm{Tây}$ Ninh [15] được xây dựng trên cơ sở kịch bản $\mathrm{BĐKH}$ và NBD cho Việt Nam 2009 [16]. Kết quả tính toán nhìn chung đã hỗ trợ tích cực cho việc hoạch định các giải pháp ứng phó $\mathrm{B} Đ K H$ trên địa bàn tỉnh. Tuy nhiên, với những thay đồi trong thời gian gần đây, cần thiết cập nhật số liệu KTTV tại địa phương cũng như kỹ thuật mô phỏng kịch bản BĐKH. Bằng phương pháp chi tiết hóa thống kê thông qua phần mềm SimCLIM, nghiên cứu này nhằm mục tiêu xây dựng kịch bản biến đổi nhiệt độ khu vực tỉnh Tây Ninh (theo các RCPs) đến năm 2100 với thời kỳ so sánh 1986-2005 và chuỗi số liệu KTTV cập nhật đến năm 2017, tạo cơ sở quan trọng để đánh giá tác động, tính DBTT do BĐKH, từ đó đề xuất các giải pháp ứng phó tương thích. SimCLIM là hệ thống phần mềm được phát triển bởi Viện Quốc tế về BĐKH toàn cầu, thuộc Đại học Waikato-Newzealand, tích hợp các kết quả đầu ra của 40 GCMs mô phỏng các yếu tố khí tượng và $24 \mathrm{GCMs}$ mô phỏng sự thay đổi của NBD, được ứng dụng thành công tại khu vực miền Trung [17] và miền Nam Việt Nam [18-20]. Các yếu tố được xem xét bao gồm nhiệt độ trung bình, nhiệt độ cực trị (tối cao và tối thấp); các hiện tượng khí hậu cực đoan (như bão, áp thấp nhiệt đới, gió mùa, rét, nắng nóng, hạn hán) không thuộc phạm vi của nghiên cứu này.

\section{Phương pháp nghiên cứu}

Sơ đồ phương pháp xây dựng kịch bản BĐKH được trình bày ở Hình 1 .

Trong nghiên cứu này, phần mền SimClim phiên bản DATAAR5REGIONAL-Downscaled spatial area for SimCLIM 2013 AR5 for South Vietnam được sử dụng. Từ kết quả của các mô hình GCMs tích hợp sẵn trong phần mềm, thực hiện chi tiết hoá (Statistical Downscaling) đến khu vực tỉnh Tây Ninh với độ phân giải $1 \mathrm{~km}$.

Số liệu thực đo nhiệt độ cực tiểu, trung bình, cực đại (Tm, Ttb, Tx) tại trạm khí tượng Tây Ninh giai đoạn 1979-2017 được thu thập (từ Đài Khí tượng Thủy văn khu vực Nam Bộ) nhằm mô tả điều kiện cụ thể của địa phương, đồng thời so sánh, đánh giá mức độ tin cậy của kết quả mô phỏng.

Mức thay đổi nhiệt độ được tính như sau:

$\Delta T_{\text {future }}=T_{\text {future }}^{*}-\overline{T_{1986-2005}^{*}}$, với $\Delta \mathrm{T}_{\text {future là }}$ mức biến đổi nhiệt độ tương lai so với thời kỳ 
cơ sở $\left({ }^{\circ} \mathrm{C}\right), \mathrm{T}^{*}$ future là nhiệt độ mô phỏng trong tương lai $\left({ }^{\circ} \mathrm{C}\right), \mathrm{T}^{*}{ }_{1986-2005}$ là nhiệt độ trung bình của thời kỳ cơ sở (1986-2005) $\left({ }^{\circ} \mathrm{C}\right)$ (Hình 1).

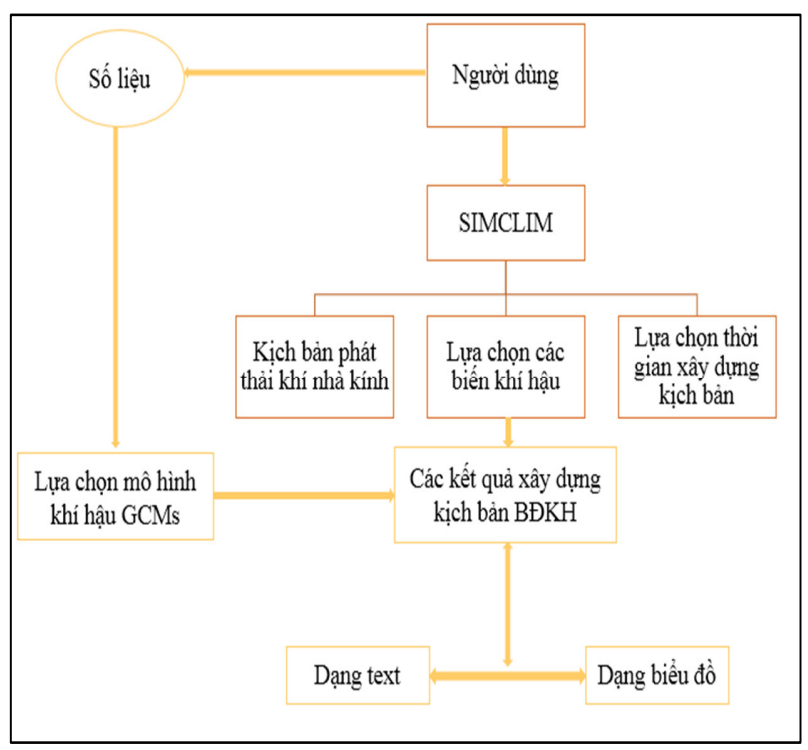

Hình 1. So đồ phương pháp xây dưng kịch bản $B Đ K H$

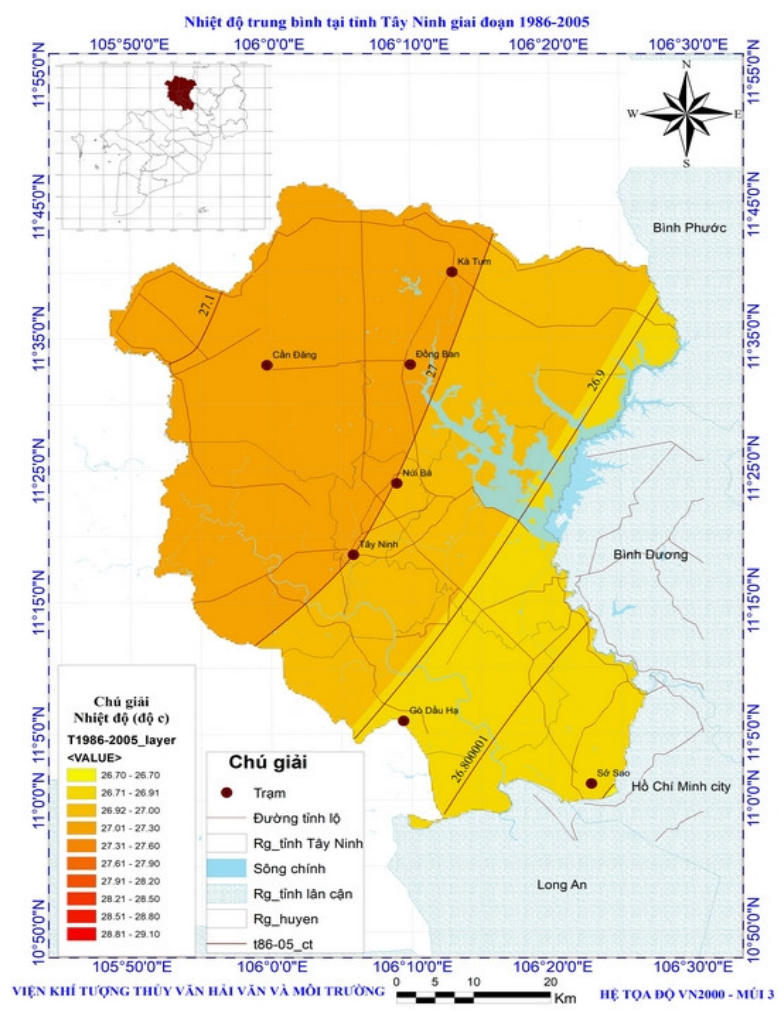

Hình 2. Nhiệt độ trung bình khu vưc tỉnh Tây Ninh giai đoạn 1986 - 2005

Các chỉ số dùng để đánh giá kết quả mô phỏng nhiệt độ gồm sai số trung bình ME (biểu thị xu thế giá trị dự báo vượt quá hay thấp hơn giá trị thực đo) và sai số tuyệt đối trung bình MAE (biểu thị độ lớn trung bình của sai số nhưng không thể hiện hướng lệch của giá trị dự báo so với giá trị quan trắc).

$$
\begin{array}{r}
M A E=\frac{1}{N} \sum_{n=1}^{N}\left|f_{n}-O_{n}\right| \\
M E(x)=\frac{1}{N} \sum_{i=1}^{N}\left(x^{f}-x^{o}\right)
\end{array}
$$

Trong đó, $\mathrm{N}$ là dung lượng mẫu; $\mathrm{f}$ và $\mathrm{O}$ lần lượt chỉ các giá trị dự báo và quan trắc. $\mathrm{ME}$ dương thể hiện xu thế dự báo của mô hình vượt giá trị thực đo và ngược lại. MAE nằm trong khoảng $(0,+\infty)$; kết quả mô phỏng hoàn hảo khi MAE bằng $0 ;$ MAE càng lớn, độ chính xác của mô hình càng kém.

Với 40 GCMs tích hợp trong SIMCLIM, 11 mô hình điển hình phù hợp với Việt Nam được lựa chọn để tính toán: ACCESS1-3 (Úc), CCSM4 (Mỹ), CMCC-CMS (Ý), CNRM-CM5 (Pháp), CSIRO-Mk3-6-0 (Úc), GFDL-CM3 (Mỹ), HADCM3 (UK), HadGEM2-AO (UK), MPI-ESM-LR (Đức), MRI-CGCM3 (Nhật) và NorESM1-M (Na Uy). Các mô hình này thuộc các trung tâm nghiên cứu khí hậu lớn trên thế giới được Bộ Tài nguyên và Môi trường sử dụng làm đầu vào cho các RCMs khi xây dựng kịch bản BĐKH cho Việt Nam năm 2016. Sai số giữa kết quả tính toán theo phương pháp chi tiết hóa thống kê tổ hợp trung vị của 11 mô hình khí hậu cho giai đoạn 1986-2005 với số liệu nhiệt độ thực đo tại trạm Tây Ninh được trình bày ở Bảng 1. Kết quả tính toán nhiệt độ trung bình (năm, mùa khô và mùa mưa) thiên thấp so với số liệu thực đo, tuy nhiên sai số không lớn và kết quả mô phỏng chấp nhận được.

\section{Kết quả và thảo luận}

\subsection{Kịch bản biến đổi nhiệt độ trung bình tại Tây Ninh}

Bảng 2 trình bày kịch bản biến đổi nhiệt độ trung bình tại Tây Ninh đến năm 2100 . 
Bảng 1. Sai số giũa mô phỏng và thực đo nhiệt độ trung bình tại trạm Tây Ninh giai đoạn 1986 - 2005

\begin{tabular}{cccc}
\hline \multirow{2}{*}{ Chỉ số đánh giá } & \multicolumn{3}{c}{ Sai số của nhiệt độ trung bình $\left({ }^{\circ} \mathbf{C}\right)$} \\
\cline { 2 - 4 } & Mùa khô & Mùa mưa & Năm \\
\hline MAE & 0.58 & 0.32 & 0.43 \\
ME & -0.58 & -0.28 & -0.42 \\
\hline
\end{tabular}

Bảng 2. Míc độ biến đổi T.tb $\left({ }^{\circ} \mathrm{C}\right)$ tại tỉnh Tây Ninh đến năm 2100 so với giai đoạn 1986 - 2005

\begin{tabular}{cccccc}
\hline Giai đoạn & Đặc trưng T & RCP2.6 & RCP4.5 & RCP6.0 & RCP8.5 \\
\hline \multirow{2}{*}{2020} & Mùa mưa & 0,5 & 0,6 & 0,6 & 0,7 \\
& Mùa khô & 0,6 & 0,6 & 0,6 & 0,7 \\
\multirow{3}{*}{2030} & Cả năm & 0,6 & 0,6 & 0,6 & 0,7 \\
& Mùa mưa & 0,7 & 0,7 & 0,8 & 1,0 \\
& Mùa khô & 0,7 & 0,8 & 0,9 & 1,0 \\
\multirow{2}{*}{2050} & Cả năm & 0,7 & 0,8 & 0,8 & 1,0 \\
& Mùa mưa & 0,9 & 1,4 & 1,4 & 1,7 \\
& Mùa khô & 1,1 & 1,4 & 1,5 & 1,8 \\
\multirow{2}{*}{2100} & Cả năm & 1,0 & 1,4 & 1,5 & 1,8 \\
& Mùa mưa & 0,9 & 1,9 & 2 & 3,6 \\
& Mùa khô & 1,2 & 2 & 2,2 & 3,6 \\
& Cả năm & 1,1 & 1,9 & 2,2 & 3,6 \\
\hline
\end{tabular}

\subsubsection{Biến đổi nhiệt độ trung bình năm}

Hình 3 cho thấy nhiệt độ trung bình năm tại tỉnh Tây Ninh gia tăng theo thời gian (20202100) với mức tăng cùng chiều với sự thay đổi các kịch bản KNK (RCP2.6-RCP8.5). Cụ thể như sau:

- Về giá trị: Đến giữa XXI, mức tăng Ttb năm Ninh so với giai đoạn 1986-2005 dao động 1,0$1,8^{\circ} \mathrm{C}$ (RCP2.6-RCP8.5). Số liệu tương ứng vào cuối XXI là $1,1-3,6^{\circ} \mathrm{C}$.

- Xu thế biến đổi giữa các mốc thời gian: có $2 \mathrm{xu}$ hướng (i) mức tăng $\mathrm{T}$ tương đối đều ở giai đoạn trước năm 2050 (khoảng $0,4^{\circ} \mathrm{C}-\mathrm{RCP} 2.6$ và $1,1^{\circ} \mathrm{C}-\mathrm{RCP} 8.5$ ), (ii) mức chênh lệch $\mathrm{T}$ đáng kể ở giai đoạn nửa cuối XXI, nhất là đối với kịch bản RCP8.5 (khoảng $1,8^{\circ} \mathrm{C}$ ). Xu thế này cũng thể hiện ở các kịch bản biến đổi nhiệt độ mùa (mùa mưa, mùa khô) cũng như nhiệt độ cực trị (cực đại, cực tiểu).

- Chênh lệch giữa các kịch bản RCP: có 2 xu hướng (i) chênh lệch không đáng kể giữa các $\mathrm{KB}$ ở giai đoạn nửa đầu XXI $\left(0,6-0,7^{\circ} \mathrm{C}\right.$ năm 2020 và $0,7-1,0^{\circ} \mathrm{C}$ năm 2030), (ii) chênh lệch khá rõ nét từ năm 2050 đến cuối XXI $\left(1,0-1,8^{\circ} \mathrm{C}\right.$ năm 2050 và $1,1-3,6^{\circ} \mathrm{C}$ năm 2100). Kịch bản RCP 4.5 và $\mathrm{RCP} 6.5$ đều thể hiện mức tăng trung bình KNK (lần lượt là trung bình thấp và trung bình cao), nên sai khác kết quả giữa 2 kịch bản này luôn luôn nhỏ ở tất cả các giai đoạn mô phỏng. Xu thế tương tự cũng được ghi nhận trong các kịch bản biến đổi một số đặc trưng khác của nhiệt độ tại tỉnh Tây Ninh đến năm 2100.

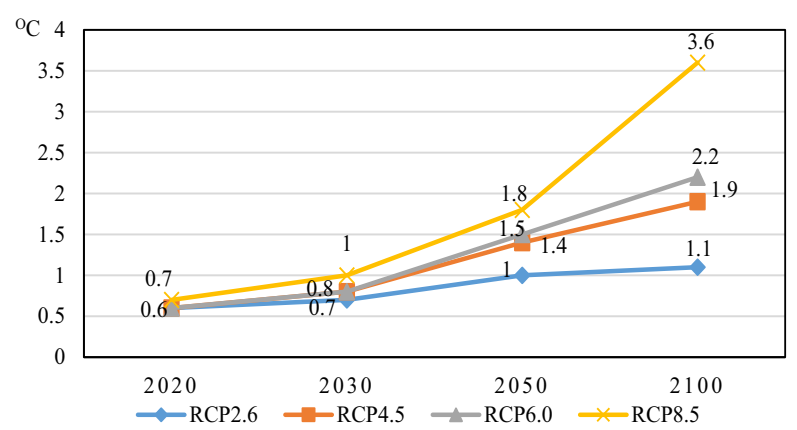

Hình 3. Mức độ biến đổi T.tb tại tỉnh Tây Ninh so với giai đoạn 1986 - 2005 

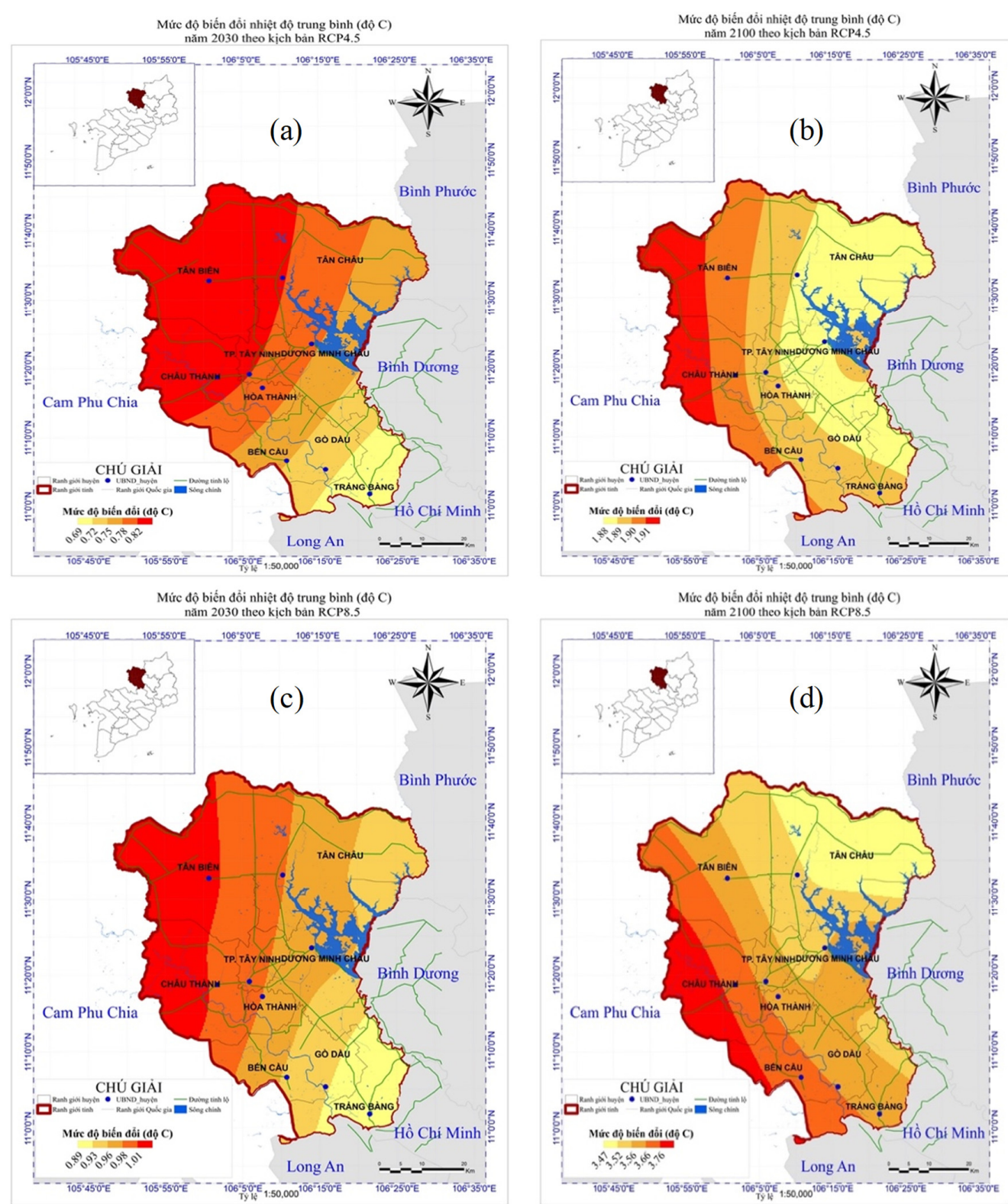

Hình 4. Mức độ biến đổi nhiệt độ trung bình năm tỉnh Tây Ninh so với giai đoạn 1986-2005: (a) Năm 2030 - RCP 4.5; (b) Năm 2100 - RCP 4.5; (c) Năm 2030 - RCP 8.5; (d) Năm 2100 - RCP 8.5

Có thể giải thích cho 02 hình thái biến đổi T.tb theo thời gian và theo RCPs như sau:

- Theo kịch bản RCP2.6, mức độ phát thải KNK là thấp nhất, bức xạ mặt trời và nhiệt độ khí quyển có xu hướng tăng chậm đến giữa thế kỷ.

- Theo RCP4.5, nồng độ KNK tăng ở mức trung bình thấp đến giữa thế kỷ, sau đó đạt mức ổn định và không có sự gia tăng đột biến nào cho đến cuối XXI. Vì thế, mức biến đổi nhiệt độ ở kịch bản RCP4.5 khá tương đồng với RCP2.6.
- Đối với RCP6.0 (cường độ bức xạ khoảng $6.0 \mathrm{~W} / \mathrm{m}^{2}$ ), nồng độ KNK tăng ở mức trung bình cao đến năm 2100 và mức tăng giảm dần trong các thập kỷ cuối XXI (với các giả thiết áp dụng công nghệ và chiến lược giảm phát thải $\mathrm{KNK}$ trong tương lai). Theo đó, nhiệt độ có xu thế gia tăng (cao hơn các kịch bản RCP2.6 và RCP4.5), đồng thời, không ghi nhận sự gia tăng đột biến vào cuối XXI.

- Ở kịch bản RCP8.5, nồng độ KNK cao nhất trong các kịch bản và tăng liên tục đến cuối thế 
kỷ XXI, kéo theo sự gia tăng đáng kể lượng bức xạ và nhiệt độ khí quyển.

Bảng 3 và hình 4 thể hiện phân bố mức độ gia tăng nhiệt độ trung bình năm tại tỉnh Tây Ninh đến năm 2100.

Bảng 3. Phân bố mức tăng nhiệt độ trung bình năm tại tỉnh Tây Ninh

\begin{tabular}{|c|c|c|c|c|c|}
\hline Kịch bản & Năm & Mức tăng & Phân bố & Cao nhất & Thấp nhất \\
\hline \multirow[t]{3}{*}{$\mathrm{RCP} 4.5$} & 2030 & $0,67-0,8^{\circ} \mathrm{C}$ & Giảm dần từ & Tân Biên, Châu Thành & Trảng Bàng \\
\hline & 2050 & $1,3-1,43^{\circ} \mathrm{C}$ & TB- ĐN & Tân Biên & Tràng Bàng \\
\hline & 2100 & $1.8-2^{\circ} \mathrm{C}$ & $\begin{array}{l}\text { Giảm dần từ } \\
\text { Tây - Đông }\end{array}$ & Tân Biên, Châu Thành & $\begin{array}{c}\text { Tân Châu, D.M. } \\
\text { Châu }\end{array}$ \\
\hline \multirow[t]{3}{*}{ RCP8.5 } & 2030 & $0,9-1,1^{\circ} \mathrm{C}$ & Giảm dần từ & Tân Biên, Châu Thành & Trảng Bàng \\
\hline & 2050 & $1,77-1,85^{\circ} \mathrm{C}$ & TB- ĐN & Tân Biên & \\
\hline & 2100 & $3,45-3,76^{\circ} \mathrm{C}$ & $\begin{array}{l}\text { Giảm dần từ } \\
\mathrm{TN} \text { - ĐB }\end{array}$ & Châu Thành & Tân Châu \\
\hline
\end{tabular}

3.1.2. Biến đổi nhiệt độ trung bình theo mùa

Bảng 2 và Hình 5 cho thấy nhiệt độ trung bình mùa tại tỉnh Tây Ninh gia tăng theo thời gian (2020-2100) và theo các kịch bản KNK (RCP2.6-RCP8.5). Về giá trị (độ lớn), mức độ gia tăng nhiệt độ chiếm ưu thế ở mùa khô, tiếp sau là trung bình năm và sau cùng là mùa mưa (tuy nhiên, sự chênh lệch này không quá lớn). Trong đó, đến cuối XXI, mức tăng T.mm và T.mk lần lượt dao động $0,9-3,6^{\circ} \mathrm{C}(\mathrm{RCP} 2.6$ $\mathrm{RCP} 8.5)$ và $1,2-3,6^{\circ} \mathrm{C}(\mathrm{RCP} 2.6-\mathrm{RCP} 8.5)$.

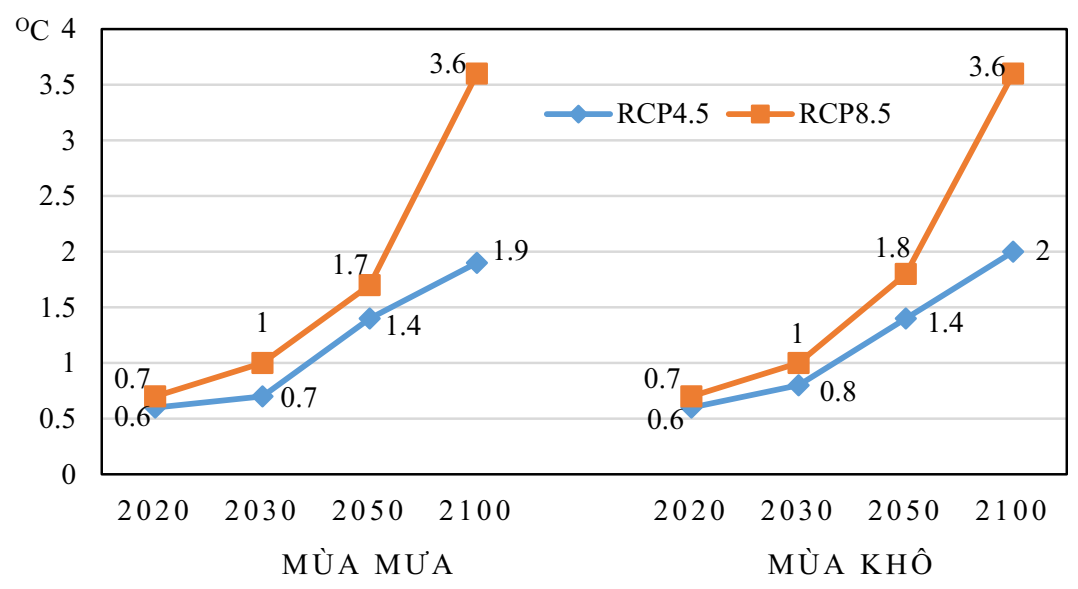

Hình 5. Mức độ biến đổi nhiệt độ trung bình mùa tỉnh Tây Ninh theo kịch bản $R C P 4.5$ và $R C P 8.5$

Phân bố mức độ biến đổi nhiệt độ trung bình mùa tỉnh Tây Ninh đến năm 2100 theo kịch bản RCP4.5 và RCP8.5 được thể hiện ở Bảng 4 và Hình hình 6.

\subsection{Mức độ biến đổi nhiệt độ cực trị}

Bảng 5-6, Hình 7-hình 8, 9 cho thấy nhiệt độ cực trị tại tỉnh Tây Ninh gia tăng theo thời gian (2020-2100) và theo các kịch bản phát thải KNK (RCP2.6-RCP8.5).

- Về giá trị:
- Mức độ biến đổi nhiệt độ tối cao (Tx): đến giữa thế kỷ XXI, mức tăng nhiệt độ Tx trung bình năm dao động $1-1,9^{\circ} \mathrm{C} \mathrm{RCP} 2.6-\mathrm{RCP} 8.5$ và tương ứng $1,1-3,8^{\circ} \mathrm{C}$ vào cuối thế kỷ. So với trung bình năm, nhiệt độ Tx mùa khô cao hơn, mùa mưa thấp hơn và có sự chênh lệch không đáng kể vào năm 2050 và 2100 khoảng $0,1-0,2^{\circ} \mathrm{C}$ ở các kịch bản.

- Mức độ biến đổi nhiệt độ tối thấp (Tm): có xu hướng tương đồng với mức tăng nhiệt độ tối 


\section{BÀI BÁO KHOA HỌC}

cao nhưng giá trị nhỏ hơn từ $0,1-0,2^{\circ} \mathrm{C}(\mathrm{RCP} 8.5)$.

- Chênh lệch giữa các mùa và giữa các kịch bản phát thải KNK

Nhìn chung, mức độ gia tăng nhiệt độ xếp theo thứ tự giảm dần như sau: mùa khô, trung bình năm, mùa mưa: lần lượt $3,9,3,8,3,8^{\circ} \mathrm{C}$ đối với Tx và $3,7,3,6,3,6^{\circ} \mathrm{C}$ đối với Tm tương ứng năm 2100-RCP8.5, cho thấy sai khác giữa các đặc trưng không đáng kể. Tương tự $\mathrm{Ttb}$, đối với Tx và $T m$, chênh lệch mức tăng nhiệt độ giữa các kịch bản RCPs chỉ thể hiện rõ nét ở nửa cuối thế kỉ XXI.

Bảng 4. Phân bố mức tăng nhiệt độ trung bình mùa tỉnh Tây Ninh

\begin{tabular}{|c|c|c|c|c|c|}
\hline \multicolumn{6}{|c|}{ Mùa mưa } \\
\hline Kịch bản & Năm & Mức tăng & Phân bố & Cao nhất & Thấp nhất \\
\hline \multirow[t]{3}{*}{ RCP 4.5} & 2030 & $0,69-0,81^{\circ} \mathrm{C}$ & Giảm dần theo & Tân Biên, Châu Thành, Tp.Tây Ninh & Trảng Bàng \\
\hline & 2050 & $1,26-1,42^{\circ} \mathrm{C}$ & hướng TB - ĐN & Tân Biên & Trảng Bàng \\
\hline & 2100 & $1,88-1,92^{\circ} \mathrm{C}$ & & Tân Biên & Trảng Bàng, Gò Dầu... \\
\hline \multirow[t]{3}{*}{ RCP 8.5} & 2030 & $0,9-1^{\circ} \mathrm{C}$ & & Tân Biên, Châu Thành & Trảng Bàng \\
\hline & 2050 & $1,6-1,8^{\circ} \mathrm{C}$ & & Tân Biên & Trảng Bàng, Gò Dầu \\
\hline & 2100 & $3,5-3,7^{\circ} \mathrm{C}$ & & Tân Biên & Trảng Bàng, Gò Dầu \\
\hline \multicolumn{6}{|c|}{ Mùa khô } \\
\hline Kịch bản & Năm & Mức tăng & Phân bố & Cao nhất & Thấp nhất \\
\hline \multirow[t]{3}{*}{ RCP 4.5} & 2030 & $0,8-0,9^{\circ} \mathrm{C}$ & Giảm dần theo & Tân Biên, Châu Thành, Tp.Tây Ninh & Trảng Bàng \\
\hline & 2050 & $1,3-1,45^{\circ} \mathrm{C}$ & hướng TB - ĐN & Tân Biên, Châu Thành & Trảng Bàng \\
\hline & 2100 & $1,9-2^{\circ} \mathrm{C}$ & & Tân Biên & Trảng Bàng \\
\hline \multirow[t]{3}{*}{$\mathrm{RCP} 8.5$} & 2030 & $0,9-1^{\circ} \mathrm{C}$ & $\begin{array}{l}\text { Giảm dần từ Tây - } \\
\text { Đông }\end{array}$ & Tân Biên, Châu Thành & Trảng Bàng \\
\hline & 2050 & $1,7-1,9^{\circ} \mathrm{C}$ & $\begin{array}{l}\text { Giảm dần theo } \\
\text { hướng TB - ĐN }\end{array}$ & Tân Biên & Trảng Bàng, Gò Dầu \\
\hline & 2100 & $3,54-3,74^{\circ} \mathrm{C}$ & $\begin{array}{l}\text { Giảm dần từ Tây - } \\
\text { Đông }\end{array}$ & Tân Biên, Châu Thành & Tân Châu \\
\hline
\end{tabular}

Bảng 5. Mức độ biến đổi nhiệt độ cực trị trung bình $\left({ }^{\circ} \mathrm{C}\right)$ tỉnh Tây Ninh so với giai đoạn 1986 - 2005

\begin{tabular}{|c|c|c|c|c|c|c|c|c|c|}
\hline \multirow{2}{*}{\multicolumn{2}{|c|}{ Đặc trưng }} & \multicolumn{4}{|c|}{ Biến đổi nhiệt độ tối cao (Tx) } & \multicolumn{4}{|c|}{ Biến đổi nhiệt độ tối thấp (Tm) } \\
\hline & & RCP & RCP & $\mathrm{RCP}$ & RCP & RCP & RCP & RCP & $\mathrm{RCP}$ \\
\hline \multirow{3}{*}{2020} & Mùa mưa & 0,5 & 0,6 & 0,6 & 0,8 & 0,6 & 0,6 & 0,6 & 0.6 \\
\hline & Mùa khô & 0,6 & 0,6 & 0,7 & 0,8 & 0,6 & 0,6 & 0,6 & 0,7 \\
\hline & Cả năm & 0,5 & 0,6 & 0,7 & 0,8 & 0,6 & 0,6 & 0,6 & 0,6 \\
\hline \multirow{3}{*}{2030} & Mùa mưa & 0,6 & 0,8 & 0,8 & 1,1 & 0,7 & 0,8 & 0,9 & 1 \\
\hline & Mùa khô & 0,7 & 1 & 0,9 & 1,2 & 0,7 & 0,9 & 0,9 & 1 \\
\hline & Cả năm & 0,7 & 0,9 & 0,8 & 1,1 & 0,7 & 0,9 & 0,9 & 1 \\
\hline \multirow{3}{*}{2050} & Mùa mưa & 0,9 & 1,5 & 1,6 & 1,9 & 1 & 1,4 & 1,5 & 1,7 \\
\hline & Mùa khô & 1,1 & 1,5 & 1,7 & 2 & 1,1 & 1,4 & 1,6 & 1,8 \\
\hline & Cả năm & 1 & 1,5 & 1,7 & 1,9 & 1 & 1,4 & 1,5 & 1,8 \\
\hline \multirow{3}{*}{2100} & Mùa mưa & 0,9 & 2 & 2 & 3,8 & 1 & 1,9 & 2,1 & 3,6 \\
\hline & Mùa khô & 1,2 & 2,1 & 2,2 & 3,9 & 1,2 & 1,9 & 2,3 & 3,7 \\
\hline & Cả năm & 1,1 & 2,1 & 2,1 & 3,8 & 1,1 & 1,9 & 2,2 & 3,6 \\
\hline
\end{tabular}


Bảng 6. Phân bố mức tăng nhiệt độ cực trị trung bình tỉnh Tây Ninh

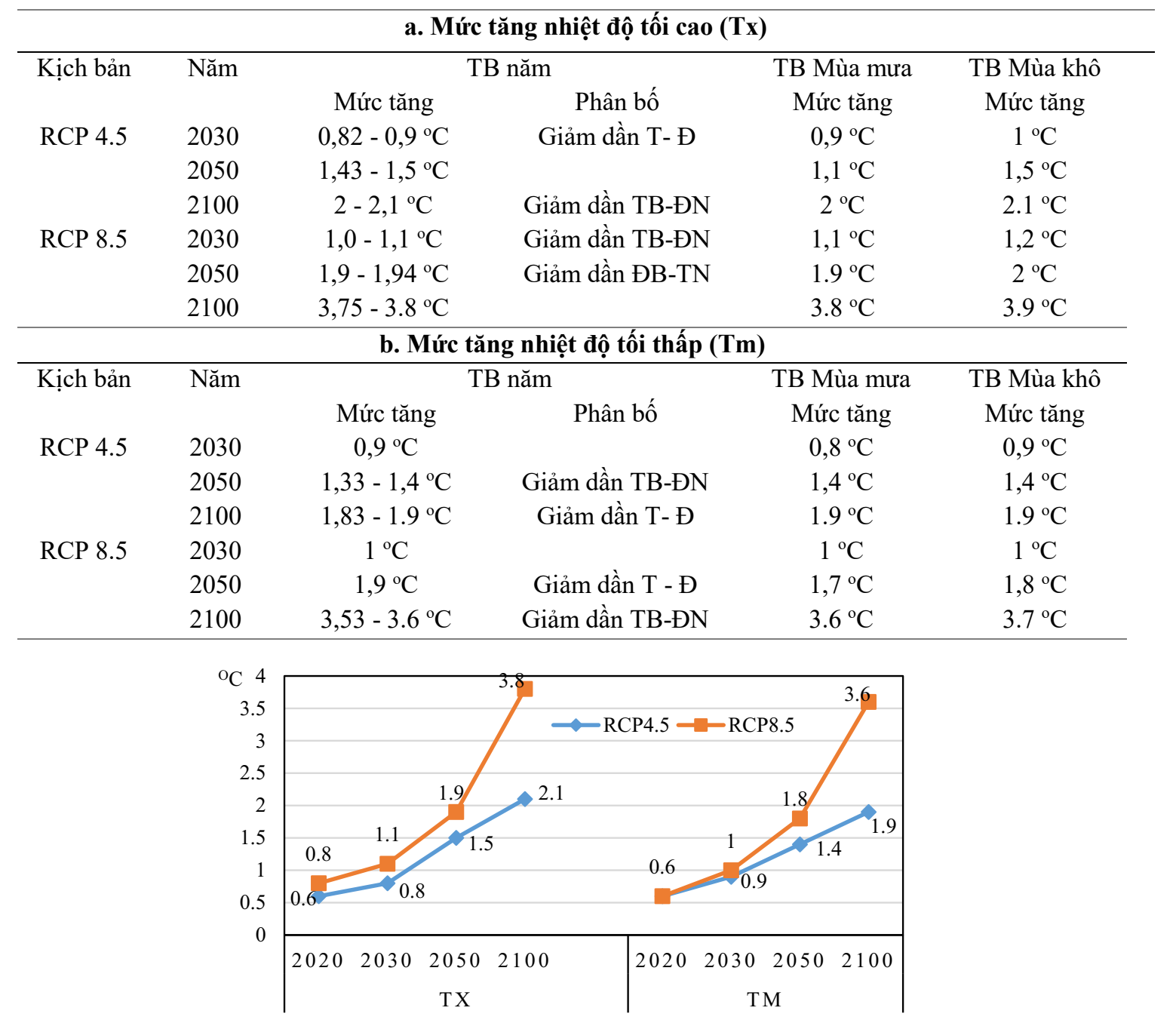

Hình 7. Mức độ biến đổi nhiệt độ cực trị trung bình năm tại tỉnh Tây Ninh

\section{Kết luận}

Bằng phương pháp thu thập, xử lý số liệu và phần mềm SimCLIM, nghiên cứu nhằm mục tiêu xây dựng các kịch bản biến đổi nhiệt độ (Tm, Ttb, Tx) tại tỉnh Tây Ninh đến cuối XXI (RCP2.6 - RCP8.5). Kết quả cho thấy nhiệt độ trung bình (Ttb) gia tăng qua các năm và các kịch bản RCP: khoảng $1,1-3,6^{\circ} \mathrm{C}$ vào năm 2100 so với giai đoạn 1986-2005. Trong đó, Ttb cao nhất phân bố chủ yếu ở khu vực phía tây (như huyện Tân Biên,
Châu Thành). Nhiệt độ các tháng trong năm cũng có dấu hiệu gia tăng theo thời gian, đặc biệt là các tháng mùa khô. Bên cạnh đó, xu thế gia tăng nhiệt độ cực trị cũng được ghi nhận với mức tăng Tx nhanh hơn so với T.tb và T.m. Kết quả nghiên cứu là cơ sở quan trọng phục vụ đánh giá tác động và tính DBTT do sự gia tăng nhiệt độ tại tỉnh Tây Ninh, đóng góp tích cực vào việc hoạch định và kiện toàn hệ thống các giải pháp ứng phó BĐKH. 


\section{BÀI BÁO KHOA HỌC}
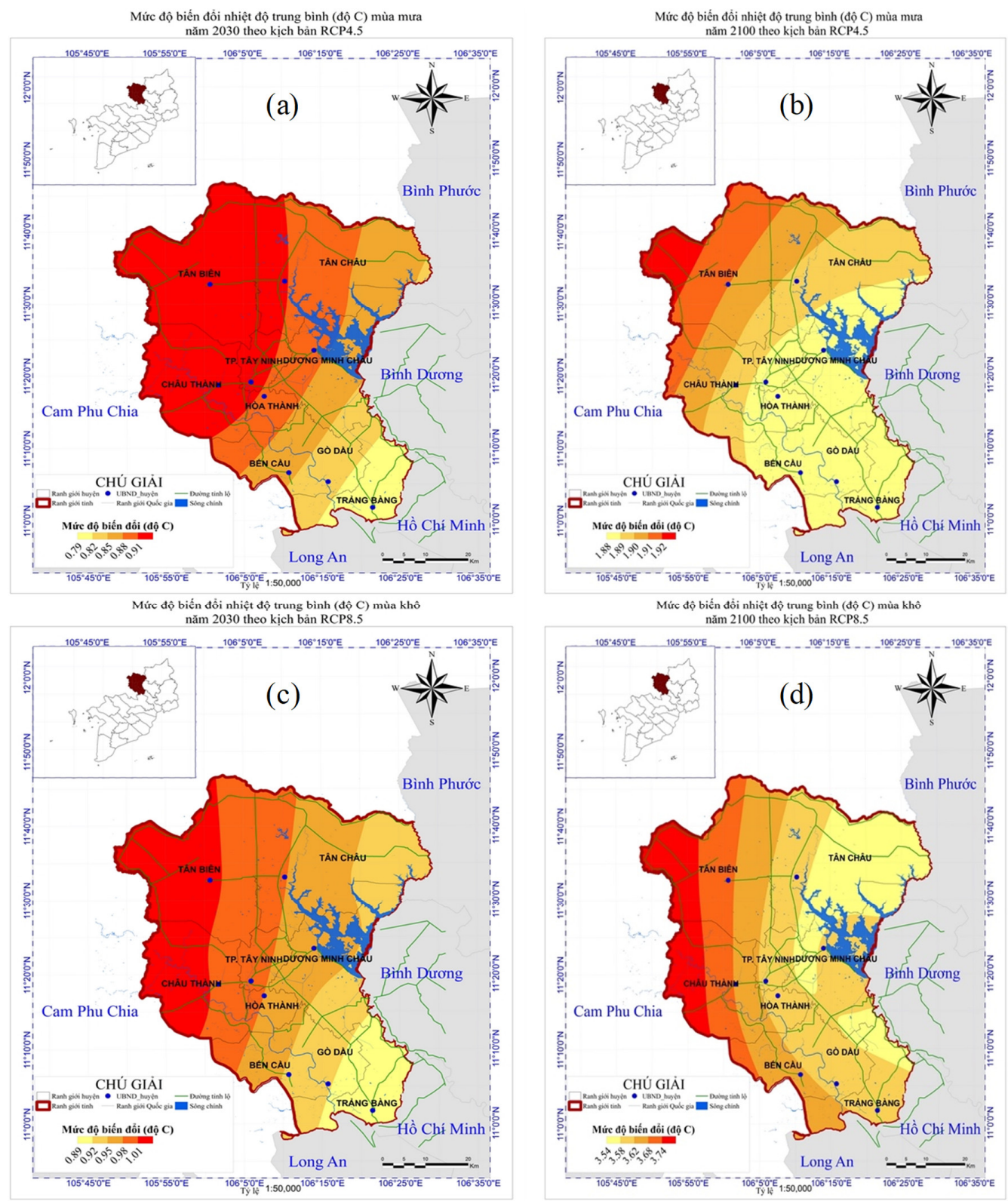

Hình 8. Mức độ biến đổi nhiệt độ trung bình mùa tỉnh Tây Ninh so với giai đoạn 1986-2005: (a)

Năm 2030, mùa mura, RCP4.5; (b) Năm 2100, mùa mura, RCP4.5; (c) Năm 2030, mùa khô, RCP8.5; (d) Năm 2100, mùa khô, RCP8.5 
BÀI BÁO KHOA HỌC

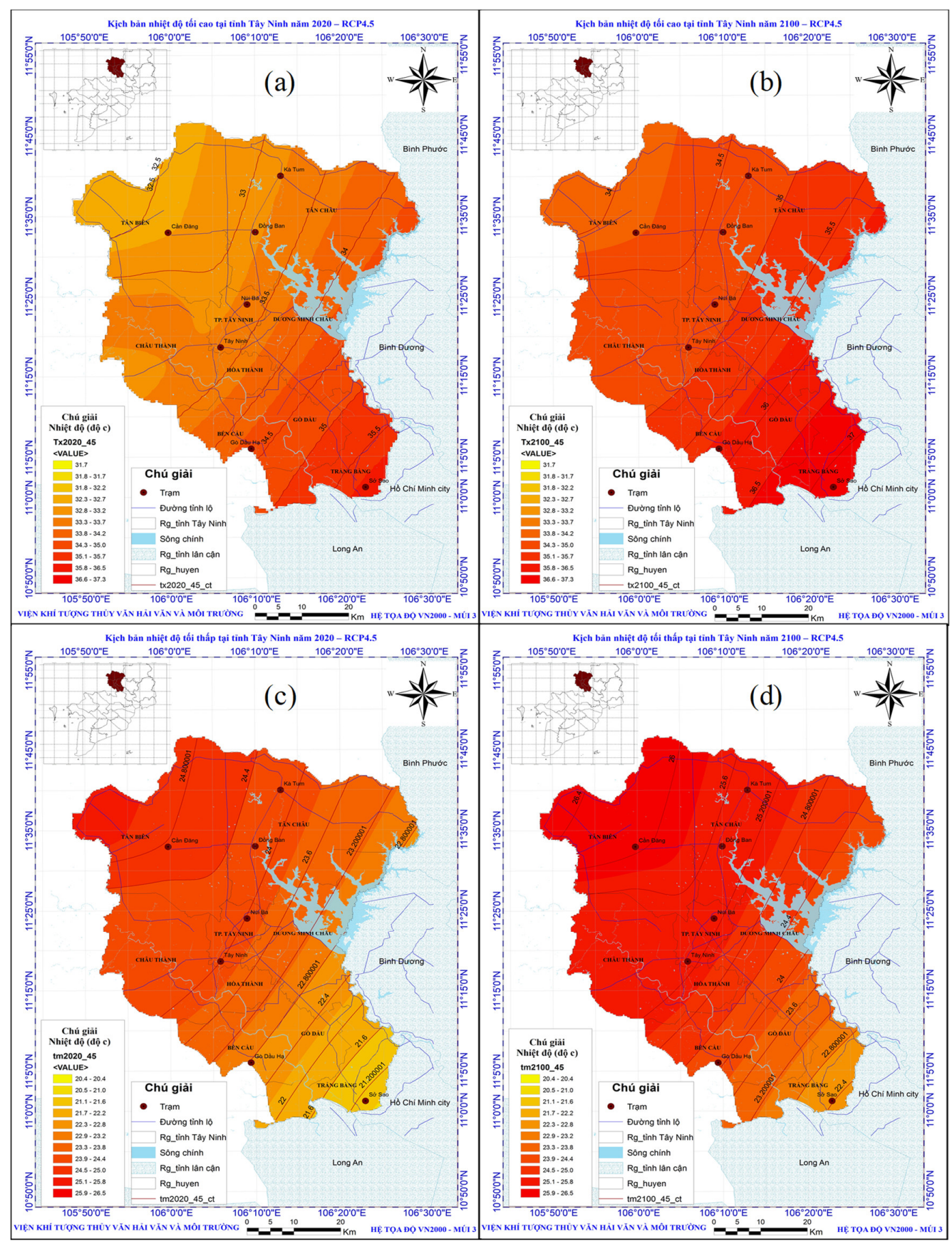

Hình 9. Phân bố nhiệt độ cực trị trung bình tại tỉnh Tây Ninh - RCP4.5: (a) Năm 2020, Tx;(b) Năm 2100, Tx; (c) Năm 2020, Tm; (d) Năm 2100, Tm 


\section{BÀI BÁO KHOA HỌC}

\section{Tài liệu tham khảo}

1. Bộ Tài nguyên và Môi trường (2016), Kịch bản Biến đổi khi hậu, nước biển dâng cho Việt Nam, Hà Nội.

2. Phan Văn Tân, Ngô Đức Thành (2013), Biến đổi khí hậu ở Việt Nam: Một số kết quả nghiên cứu, thách thức và co hội trong hội nhập quốc tế. Tạp chí Khoa học ĐHQGHN, Các Khoa học Trái đất và Môi trường, 29 (2), 42-55.

3. Hildebrandsson, H.H., (1897), Quelques recherches sur les entres d'action de l'atmosphère, K. Svenska Vetens - Akad. Handl., 29, 33.

4. Walker, G.T. (1923), Correlation in seasonal variability of weather, VIII. A preliminary study of world weather. Memoirs of the India Meteorological Department, 24, 75-131.

5. Barnston, A.G., Ropelewski, C.F., (1992), Prediction of ENSO episodes using Canonical Correlation Analysis. Journal of Climate, 5, 1316-1345.

6. Tangang, F.T., Hsieh, W.W., Tang, B., (1997), Forecasting of equatorial Pacific sea surface temperatures by neural networks models. Climate Dynamics, 13, 135-147.

7. Barnston, A.G., Thiao, W., Kumar, V., (1996), Long-lead forecasts of seasonal precipitation in Africa using CCA. Weather and Forecasting, 11, 506-520.

8. Ward, M.N., Folland, C.K., (1991), Prediction of seasonal rainfall in the north of Nordeste of Brazil using eigenvectors of sea surface temperature. International Journal of Climatology, 11, 711743.

9. Colman, A.W., (1997), Prediction of summer central England temperature from preceding North Atlantic winter sea surface temperature. International Journal of Climatology, 17, 1285-1300.

10. Phan Văn Tân (2010), Nghiên cưu tác động của biến đổi khi hậu toàn cầu đến các yếu tố và hiện tượng khí hậu cực đoan ở Việt Nam, khả năng dụ báo và giải pháp chiến lược ứng phó. Chương trình KHCN cấp nhà nước KC08/06-10. Mã số đề tài: KC08.29/06-10.

11. Kleeman, R., Moore, A.M., Smith, N.R., (1995), Assimilation of sub-surface thermal data into an intermediate tropical coupled ocean-atmosphere model. Monthly Weather Review, 123, 31033113.

12. Cane, M.A., Zebiak, S.E., Dolan, S.C., (1986), Experimental forecasts of El Nino. Nature, 321, 827-832.

13. Chakraborty A., Krishnamurti, T.N., (2006), Improved seasonal climate forecasts of the South Asian summer monsoon using a suite of 13 coupled ocean-atmosphere moedels. Monthly Weather Review, 134, 1697-1721.

14. IPCC (2007), Climate Change 2007: Climate Change Impacts, Adaptation and Vulnerability, Summary for Policy Makers, Contribution of Working Group II to the Fourth Assessment Report of the Intergovernmental Panel on Climate Change, Cambridge University Press, Cambridge and New York.

15. UBND tỉnh Tây Ninh (2013), Kế hoạch hành động ưng phó với BĐKH tỉnh Tây Ninh.

16. Bộ Tài nguyên và Môi trường (2009), Kịch bản Biến đổi khi hậu, nuớc biển dâng cho Việt Nam, Hà Nọi.

17. UBND tỉnh Bình Định (2017), Cập nhật Kế hoạch hành động ứng phó với BĐKH tỉnh Bình Định.

18. UBND tỉnh Vĩnh Long (2016), Cập nhật Kế hoạch hành động ứng phó với BĐKH tỉnh Vĩnh Long.

19. Lê Ngọc Tuấn, Ngô Nam Thịnh, Nguyễn Kỳ Phùng (2018), Xây dụng kịch bản mực nước biển dâng trong bối cảnh biến đổi khi hậu cho khu vục thành phố Hồ Chí Minh. Tạp chí Phát triển Khoa 
học và Công nghệ. Chuyên san KHTN, 2 (5), 184-191.

20. Ky Phung Nguyen, Van Tin Nguyen, Ngoc Tuan Le (2017), Precipitation scenarios in Ho Chi Minh city in the context of climate change. Vietnam Journal of Science and Technology, 55 (4C), 115-121.

\title{
TEMPERATURE SCENARIOS IN TAYNINH PROVINCE IN THE CONTEXT OF CLIMATE CHANGE
}

\author{
Le Ngoc Tuan ${ }^{1 *}$, Nguyen Van Tin ${ }^{2}$, \\ Tran Tuan Hoang ${ }^{2}$, Pham Thanh Long ${ }^{2}$, Nguyen Ky Phung ${ }^{3}$ \\ ${ }^{1}$ University of Science - Vietnam National University Hochiminh City \\ ${ }^{2}$ Sub-Institute of HydroMeteorology and Climate change \\ ${ }^{3}$ Department of Science and Technology - Hochiminh City
}

\begin{abstract}
By data collecting and processing method and SimCLIM software, this work aimed at developing temperature scenarios in Tay Ninh province corresponding to RCP2.6, RCP4.5, RCP6.0, and RCP8.5 scenarios. Results showed the average temperature (TTB) would increase over the time and RCPs: $1.1^{\circ} \mathrm{C}$ to $3.6^{\circ} \mathrm{C}$ in 2100 compared to that in the period of 1986-2005. The highest TTB would distribute in the west (such as Tan Bien and Chau Thanh districts). The study also recorded the increase trend of monthly TTB (especially in the summer) and of extreme temperatures where the increase in Tx would be faster than TTB and Tm. These results are an important basis for assessing impacts and vulnerability due to temperature rise in particular and climate change in general in Tay Ninh province.
\end{abstract}

Keywords: Climate change scenario, extreme temperature, temperature evolution, global warming. 